\title{
Impacts of Ontario Legislation (Bill 148 and 47) on The Gender Gap and The Glass Ceiling
}

\author{
Moradeyo Adeniyi ${ }^{1}$ \\ ${ }^{1}$ Affiliation not available
}

April 28, 2020

Over the last few years, up until 2018, the Liberal Party of Ontario has consistently been in power (Elections Ontario 2018). During its leadership, Bill 148 - a plan for fair workplaces and better jobs was passed. This bill sought to amend the identified gaps in Ontario's workforces through remedies formed to create a more just and unprejudiced environment for employees and employers. Some of the changes highlighted in Bill 148 include the increase of the hourly wage to $\$ 14$ per hour (with a proposed increase to $\$ 15$ per hour in January 2019), an enforcement of the equal pay for equal work rule, extended accessibility to job-protected emergency days, an increase of the range of paid vacation and so forth (Ontario 2018). More notably, an accommodation was made for victims of domestic or sexual abuse which grants between 10 days to 15 weeks of leave if a worker or their child has been threatened or abused (Ontario 2018). These proposed changes, some of which are already in effect, also have exceptions. Worthy of notice is that demographic characteristics such as race, gender and status explicitly are not qualified as a premise for a gap in employee wages (Ontario 2018). For this paper, gender is of specific importance.

However, the general elections that took place in June 2018 resulted in a transition of power from the Liberal Party to the Progressive Conservative Party of Ontario. Similarly, a bill titled Making Ontario Open for Business Act has been brought forward and a lot of its proposed changes are counter-intuitive to those implemented in Bill 148. Legislations such as the increase to $\$ 15$ wage per hour and paid absence for sick days have been retracted while changes in regard to parity, paid vacation and domestic/sexual abuse remain the same (Mojtehedzadeh 2018). However, as opposed to Bill 148 that permits employees to ask for a review of their pay in a case where they feel they are being underpaid for the work they do (Ontario 2018), Bill 47 withdraws this authorization. This means workers who are getting paid less for the same amount of work as their colleagues are not allowed to file complaints (Mojtehedzadeh 2018).

If the bill is passed, it is more likely to adversely affect women in the workforce.

\section{The Gender Pay Gap}

Research has shown that pay, to a large extent, is affected by gender. As defined by the Canadian Women's Foundation, gender pay gap essentially refers to "the difference in earnings between women and men in the workplace" (Canadian Women's Foundation 2018). The primary cause of the gender pay gap is occupational sex segregation i.e. the concentration of workers of a certain demographic feature (gender) into different occupations. Mostly, the case is that men are being paid more than women and sometimes it is for the same job. Gender pay gap may differ depending on what is being used to measure it i.e. either wage per hour or earnings over a duration of time. In Canada, the gender gap in annual earnings is somewhat significant while the gap in wages is considerably lower (Kervin 2018). Canadian women statistically earn almost 30\% less than men do (Canadian Women's Foundation 2018). This is partly as a result of women being more likely to have non-linear careers and also due to the tendency of women working fewer hours than men for a number of reasons (majorly childcare and social culture amongst others). 


\section{What is the effect of these bills on the Gender Pay Gap?}

As stated in Bill 148, companies should not "pay one employee less than another employee, because their employment status is different, if both people perform equal work." (Ontario 2018). While the differences in status here refer mostly to the type of job held by the employee e.g. full time, seasonal, part time, etc., this legislation also explicitly states that gender is not an admissible premise for unequal pay. Furthermore, it grants the consent to challenge the employer if this rule is not being implemented in the workplace. This makes gender parity in the workplace seem more achievable because it will allow women challenge any sort of pay discrimination that is seemingly based on gender and not skill or work. As employers are required to respond to such requests with an updated pay rate or a well-informed analysis of the gap (Ontario 2018), it makes it harder for companies and organizations to marginalize women. The repeal of this change by the probable legislation of Bill 47 will undo this great leap towards egalitarianism in the workplace. The equal pay for genders is still enforced but with this bill, women will not be able to challenge their employers when they do not implement this rule. In situations where women are being paid less for the same work as their male counterparts, they will no longer have the leverage to question this injustice and be assured a remedy or at least, a response.

\section{The Glass Ceiling}

Women and men tend to be promoted at the same rate, but this is only up to a certain stage in their respective occupations. Once that point is reached, men are more likely to get promoted to senior positions (Kervin 2018). Regardless of the work they put in, it is more difficult for women to get past this point that is if they do at all. Simply put, the gendered glass ceiling is a prejudiced barrier that stops women from reaching positions of high authority in their careers simply because they are women. For instance, female professors tend to be less likely to get promoted to full professors in comparison with male professors (Kervin 2018). However, there is a gradual (and occasionally stagnant) trend of women having increased representation in senior management positions.

\section{Relationship between both bills and the Glass Ceiling}

Different organizations use either or both promotion models: the seniority model and the merit model (Kervin 2018). The seniority model considers years spent at the job and promotes those with unbroken streaks of employment in the organization they work in. On the other hand, the merit model is a more rational approach and promotes workers based on how well they perform their allocated tasks. As part of its exceptions regarding "equal pay for equal work", Bill 148 plainly states that this change does not apply if the difference in pay is based on the merit or seniority model (Ontario 2018). This is problematic for a variety of reasons. Though the seniority model is purportedly better for women because of the reduced likelihood of gendered discrimination and/or bias, there are factors such as child rearing (which spirals down into outdated experience) that cause women to have non-linear careers and lapses in their work experience. The ambiguity of the merit model also puts women at the shorted end of the stick as the 'merit' is based on assessment which could be subjective especially with the overt homophily in organization culture. The exception of unequal pay based on either of these models is unfair to women because there is a possibility within either model that women may be disadvantaged. This exception provides the opportunity for employers to mask gender-based discrimination under the guise of either model of promotion. Notwithstanding, Bill 47 does not repeal protected leave for domestic or sexual abuse. As women are more likely to be victims of abuse, the protected leave protects their jobs which is beneficial where the seniority model is being used. Yet, Bill 47 reduces the number of emergency days granted to employees. Women reportedly are more likely to take leave days for familial responsibilities and if Bill 148 is annulled, the increased inflexibility of organizations may lead to more women cutting their chances of getting promoted to senior positions of authority by opting out of the workforce (Kervin 2018). 
To conclude, bills have similar chances of being detrimental or beneficial to women due to lapses in the regulations and amendments. The government of Ontario can create a bill that specifically aims to address and remedy the systematic and institutional marginalization of women in the workforce to get rid of these side-effects of the passed legislations.

\section{References}

Canadian Women's Foundation. 2018. The Facts about the Gender Wage Gap in Canada. August.

Elections Ontario. 2018. Election Results - June 7, 2018 general election poll by poll results. June.

Kervin, John. 2018. "Intro and 6 problems." SOC362 Sex, Gender and Work. Lecture 1. September 6.

Kervin, John. 2018. "Gender and Compensation." SOC362 Sex, Gender and Work. Lecture 7. November 1.

Kervin, John. 2018. "Organizations and Glass Ceilings." SOC362 Sex, Gender and Work. Lecture 5. October 18.

Kervin, John. 2018. "Work-life Conflict." SOC362 Sex, Gender and Work. Lecture 10. November 15.

Mojtehedzadeh, Sara. 2018. "How your rights on the job will change if Bill 47 is passed". Retrieved November 12, 2018 (https://www.thestar.com/news/queenspark/2018/10/26/how-your-rights-on-the-job-will-changeif-bill-47-is-passed.html)

Ontario. 2018. A plan for fair workplaces and better jobs (Bill 148). August.

Wilson, Jim. 2018. Bill 47 - An Act to amend the Employment Standards Act, 2000, the Labour Relations Act, 1995 and the Ontario College of Trades and Apprenticeship Act, 2009 and make complementary amendments to other Acts. Legislative Assembly of Ontario. 